\title{
PERBEDAAN EFEKTIFITAS PENGGUNAAN ATRAKTAN LARUTAN FERMENTASI GULA-RAGI DAN AIR RENDAMAN CABAI MERAH (Capsicum Annum) TERHADAP JUMLAH TELUR Aedes Sp. YANG TERPERANGKAP
}

\author{
EFFECTIVENESS OF THE USE OF ATTRACTANT SOLUTION OF \\ YEAST-SUGAR AND WATER SOAKING RED CHILII (Capsicum annum) \\ TO THE NUMBER OF TRAPPED EGGS OF Aedes sp
}

\author{
Arvita Kumala Sari, Devi Octaviana, Siwi Pramatama MW \\ Jurusan Kesehatan Masyarakat Fakultas Ilmu-Ilmu Kesehatan \\ Universitas Jenderal Soedirman
}

\begin{abstract}
Oviposition trap (Ovitrap) is one of the Aedes sp mosquito controlling method without insectide. The purpose of this study was to determine the effectiveness of the use of attractant solution of yeast-sugar and water soaking red chilii to the number of trapped eggs of Aedes sp. Type of this research was experimental study. The subject of this research were all the eggs were trapped on ovitrap, while the research unit was a group of houses, building / construction in the research area which consisted of 15 houses. The study was conducted in kelurahan Mersi,Mersi District of Purwokerto. This research applies 3 treatment, so that the object consists of 15 houses with the total number of installed ovitrap 45 indoors and 45 outdoors.

Total number of eggs of Aedes sp which trapped in ovitrap were 1021 grain. Number of trapped eggs in control (water wells), water of soaking red chili attractant and solution of yeast-sugart attractant were 929 grains (91\%), 60 grains (5,9\%) and 32 grains (3.1\%) respectively. Number of eggs which trappped in ovitrap outdoor were 639 grains (62.6\%) while in ovitrap indoor wwere 382 grains (37.4\%). There was significant difference in the number of eggs that trapped in each type of attractant, however there was no significant difference in the number of eggs that are trapped on the basis of location.
\end{abstract}

Keywords : Soakingred chili, solution of yeast-sugar, attractant, egg of Aedes sp

\section{ABSTRAK}

Perangkap oviposisi (ovitrap) adalah salah satu metode pengendalian nyamuk Aedes sp tanpa insektisida. Tujuan dari penelitian ini adalah untuk mengetahui keefektifan penggunaan larutan atraktan ragi-gula dan air perendaman cabe merah terhadap jumlah telur terperangkap di Aedes sp.

Jenis penelitian ini adalah penelitian eksperimental. Subjek penelitian ini adalah semua telur yang terjebak dalam ovitrap, sedangkan unit penelitian adalah kelompok rumah, bangunan / konstruksi di daerah penelitian yang terdiri dari 15 rumah. Penelitian dilakukan di kelurahan Mersi, Kecamatan Mersi, Purwokerto. Penelitian ini menggunakan 3 perlakuan, sehingga objek terdiri dari 15 rumah dengan jumlah ovunerit terpasang 45 di dalam ruangan dan 45 di luar rumah.

Jumlah telur Aedes sp yang terperangkap dalam ovitrap adalah 1021 butir. Jumlah telur yang terperangkap dalam kontrol (sumur air), air rendaman cabai merah dan larutan atraktan ragi-sugart masing-masing adalah 929 butir (91\%), 60 butir (5,9\%) dan 32 butir (3,1\%). Jumlah telur yang digantung di ovitrap outdoor adalah 639 butir (62,6\%) sedangkan di ovitrap indoor sebanyak 382 butir $(37,4 \%)$. Ada perbedaan signifikan dalam jumlah telur yang terjebak pada masing-masing jenis atraktan, namun tidak ada perbedaan signifikan dalam jumlah telur yang terjebak berdasarkan lokasi.

Kata kunci: Perendaman cabai merah, larutan ragi-gula, atraktan, telur Aedes sp 


\section{PENDAHULUAN}

Nyamuk Aedes aegypti dan Aedes albopictus memiliki peranan penting dalam penularan beberapa penyakit. Penyakit yang dapat dan Hemorrhagic Fever; DHF) Chikungunya yang sering menimbulkan epidemi dan Kejadian Luar Biasa (KLB) di daerah tropis dan subtropis, termasuk Indonesia. Jumlah penderita DBD di Indonesia pada tahun 2014 dilaporkan sebanyak 100.347 kasus dengan jumlah kematian sebanyak 907 orang, angka kesakitan / Incidence Rate (IR) 39,8 per 100.000 penduduk dan angka kematian / Case Fatality Rate (CFR) 0,9\%. Jumlah kasus DBD menurun pada tahun 2015 yaitu sebanyak $\quad 7.244 \quad$ kasus.(Profil Kesehatan Indonesia, 2015).Angka kasus DBD di Kabupaten Banyumas terbanyak berada di wilayah kerja Puskesmas 1 Purwokerto Timur. Menurut Profil Puskesmas 1 Purwokerto Timur, data kasus penderita DBD di wilayah kerjanya mencapai 81 kasus pada Tahun 2015. Kemudian sampai akhir Maret 2016 terdapat 52 kasus DBD yang dilaporkan ke puskesmas.
Pemberantasan nyamuk Aedes aegypti akan lebih efektif jika berdasarkan Pemeriksaan Jentik Berkala (PJB) yang dilakukan oleh petugas puskesmas dan menghitung ABJ secara rutin setiap sebulan sekali. Angka bebas jentik merupakan indikator keberadaan jentik nyamuk di dalam kontainer atau rumah.Manajemen pengendalian ketika angka bebas jentik rendah berarti keberadaan jentik pada suatu rumah semakin tinggi sehingga diperlukan pengendalian vektor dalam pemberantasan penularan penyakit DBD (Achmadi, 2008). Nilai Angka Bebas Jentik (ABJ) yang terburuk dalam 2 bulan terakhir terdapat di Kelurahan Mersi yang hanya mencapai $91,13 \%$ pada Bulan Februari, dan 93\% pada Bulan Maret. Angka ini di bawah batas nilai ABJ yang dianjurkan oleh pemerintah yaitu sebesar $95 \%$.

Upaya penanggulangan DBD dengan melakukan pengendalian vektor baik secara fisik, kimia maupun biologi.Upaya pengendalian kimia saat ini masih diminati oleh masyarakat karena hasilnya bisa langsung dan cepat dalam membunuh nyamuk 
dewasa.Pengendalian secara alami menggunakan bahan nabati atau tanaman merupakan salah satu alternatif.Pengendalian secara alami menggunakan bahan nabati atau tanaman merupakan salah satu alternatif pengendalian yang ramah lingkungan, mudah diaplikasikan dan tidak berbahaya bagi musuh alami dan serangga menguntungkan lainnya.Selain ini bahan nabati mempunyai tingkat keamanan lebih tinggi dibandingkan dengan racun anorganik. Salah satu cara pengendalian nyamuk Aedes sp. yang berhasil menurunkan densitas vektor di beberapa negara adalah penggunaan perangkap telur (ovitrap) berupa peralatan untuk mendeteksi keberadaan nyamuk Aedes aegypti dan Aedes albopictus.

Perangkap nyamuk agar lebih efektif dikombinasikan dengan media atraktan yang disukai nyamuk Aedes aegypti.Penelitian tentang efektifitas atraktan yang menentukan efektifitas kerja trapping telah dilakukan sebelumnya, salah satunya oleh Astuti dan Nusa (2011) yang menyatakan bahwa fermentasi gula dengan ragi akan menghasilkan bioetanol dan $\mathrm{CO} 2$, diharapkan senyawa tersebut mampu menarik nyamuk (atraktan). Penelitian lainnya mengenai atraktan dilakukan oleh Rahayu dkk., (2015) yang menyatakan bahwa atraktan air rendaman cabai $15 \%$ efektif untuk menarik nyamuk karena mengandung amonia, CO2, asam laktat, octenol dan asam lemak.

Berdasarkan fakta-fakta tersebut, peneliti tertarik untuk membandingkan “ Perbedaan Efektifitas larutan fermentasi gularagi dan air rendaman cabai merah (Capsicum annum) terhadap jumlah telur Aedessp. yang terperangkap pada ovitrap di Kelurahan Mersi Purwokerto Timur".

\section{METODE PENELITIAN}

Penelitian ini termasuk penelitian experiment yaitu penelitian yang memberikan manipulasi terhadap independent variable. Banyaknya perlakuan dalam penelitian ini adalah 3 macam perlakuan menggunakan larutan fermentasi gula-ragi, air rendaman cabai merah, dan air sumur sebagai kontrol.Skema rancangan penelitian menggunakan post test only control group design. Penelitian dilakukan di 
kawasan RW 4 RT 4 Kelurahan

Mersi Kecamatan Purwokerto Timur, Kabupaten Banyumas yang merupakan daerah endemis DBD.Penelitian dilakuakan dengan meletakkan masing-masing 3 ovitrap baik dalam dan di luar rumah dengan setiap kelompok perlakuan.

Populasi penelitian adalah telur nyamuk Aedes sp. dan sampelnya adalah telur nyamuk Aedes sp. yang berada dalam lokasi penelitian.Unit penelitiannya adalah sekelompok rumah/bangunan yang berada dalam lokasi penelitian yaitu Kelurahan Mersi sebanyak 15 rumah.Penentuan unit penelitian dilakukan berdasarkan penilaian daerah RW yang ABJ nya rendah namun dalam satu bulan terakhir tidak terdapat kasus DBD dan tidak

Tabel 4.1. Hasil pengamatan suhu dan $\mathrm{pH}$ atraktan

\begin{tabular}{llll}
\hline Atraktan & Suhu $\left({ }^{0} \mathrm{C}\right)$ & $\mathrm{pH}$ & Warna \\
\hline Larutan fermentasi gula-ragi & 24 & 6 & Putih keruh \\
Rendaman cabai merah & 25 & 5 & Kekuningan \\
Kontrol & 27 & 7 & Bening \\
\hline
\end{tabular}

Jumlah keseluruhan telur nyamuk Aedes sp yang terperangkap pada ovitrap berdasarkan seluruh rumah pemasangannya berjumlah 1021 butir, yaitu hasil dari pemasangan 90 ovitrap.Jumlah telur yang terperangkap paling banyak terdapat pada kontrol (air sumur), dilakukan fogging.Data jumlah dan rata-rata (mean) telur nyamuk yang terperangkap berdasarkan jenis atraktan dan letak pemasangan ovitrap ditampilkan dengan menggunakan tabel distribusi frekuensi.Efektifitas perlakuan dengan Uji Kruskal Wallis pada perlakuan masing-masing atraktan kemudian Uji Mann Whitney sebagai uji lanjut.

\section{HASIL DAN PEMBAHASAN}

Hasil pengamatan dan pengukuran suhu dan $\mathrm{pH}$ udara seperti yang tercantum dalam Tabel.4.1 menunjukkan perbedaan suhu antara 2 jenis atraktan dan kontrol yang digunakan dalam penelitian. 
berkode 13 paling sedikit yaitu 11 butir $(1,1 \%)$.

Hasil pengukuran suhu atraktan larutan fermentasi gula ragi, rendaman cabai merah dan kontrol (air sumur) berturut-turut $24 \mathrm{oC}$, $25 \mathrm{oC}, 27 \mathrm{oC}$. Suhu tersebut masih merupakan suhu yang optimum untuk tempat bertelurnya nyamuk.Seperti yang dinyatakan oleh Pedrosa (2010) mengenai dampak variasi suhu dan kelembaban terhadap kegiatan reproduksi dan kelangsungan hidup nyamuk Aedes aegypti, pada suhu $25 \mathrm{oC}$ potensial untuk tingkat oviposisi nyamuk.Derajat keasaman $(\mathrm{pH})$ ketiga atraktan yang digunakan yaitu larutan fermentasi gula ragi, air rendaman cabai merah dan kontrol berturut-turut 6, 5, 7. Menurut Jacob dkk., (2014) derajat keasaman (pH) air perindukan merupakan faktor yang sangat menentukan kelangsungan hidup dan pertumbuhan nyamuk Aedes sp. Perkembangbiakan nyamuk Aedes sp dapat dipengaruhi oleh $\mathrm{pH}$ air perindukan, sesuai dengan penelitian yang dilakukan Agustina (2013) nyamuk Aedes sp dapat hidup di wadah yang mengandung air dengan pH 5,8 - 8,6. Hal ini disebabkan karena nyamuk Aedes sp tidak mampu bertahan atau mati pada saat $\mathrm{pH} \leq 3$ dan $\geq 12$.Aedes sp tidak mampu berkembang menjadi dewasa.

Tabel 4.2 Distribusi jumlah telur Aedes sp yang terperangkap berdasarkan rumah pemasangan

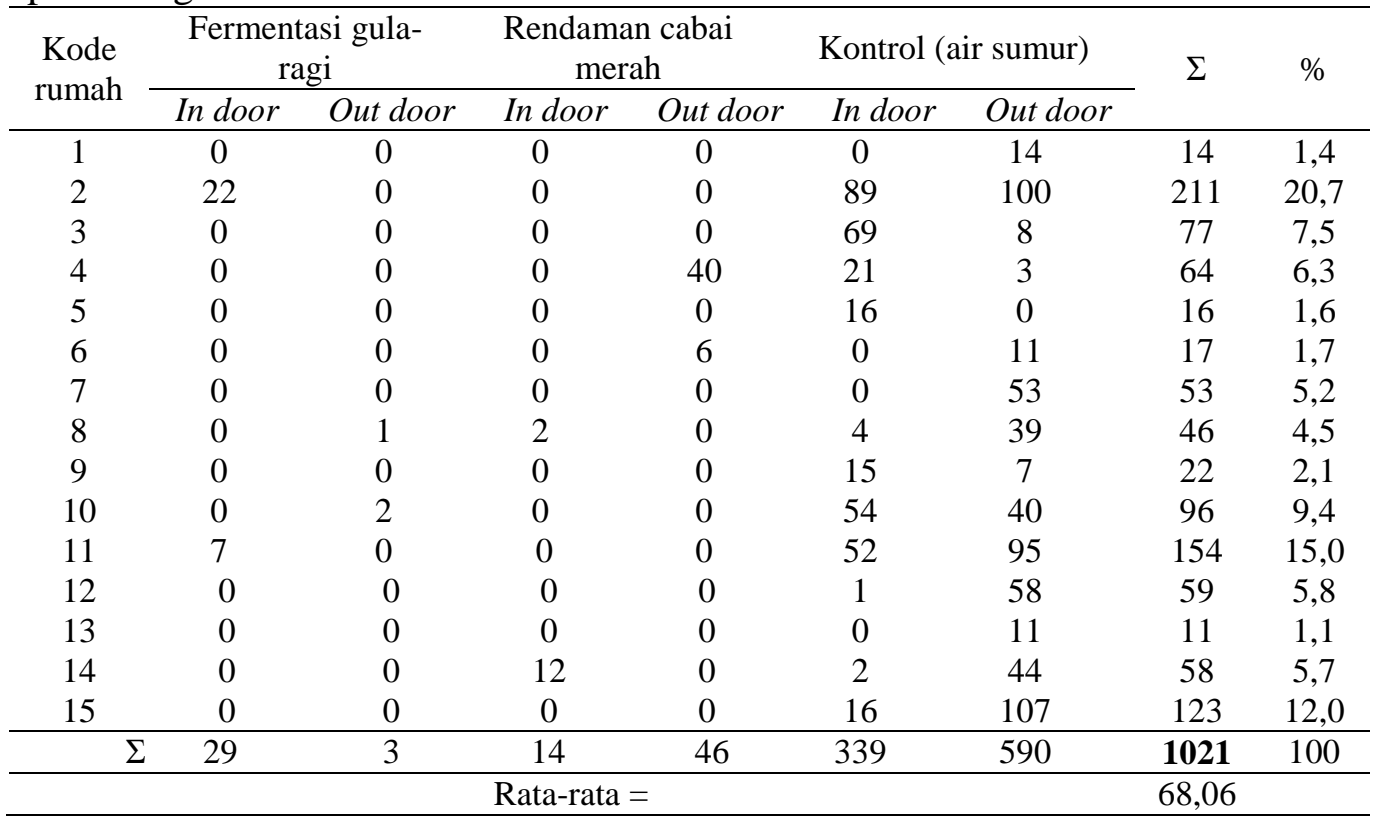


Perhitungan Indeks Ovitrap (IO) didapatkan dari seluruh jumlah ovitrap positif telur dibagi ovitrap yang diperiksa yaitu $36,66 \%$. Angka indeks ovitrap tersebut masuk dalam Tabel 4.4 Hasil Perhitungan Indeks Ovitrap $(I O)$

\begin{tabular}{lcc}
\hline \multirow{2}{*}{ Ovitrap yang Positif Telur } & \multicolumn{2}{c}{ Letak Pemasangan } \\
\cline { 2 - 3 } & In door & Out door \\
\hline Ovitrap (+) & 15 & 18 \\
Ovitrap (-) & 30 & 27 \\
\hline Total & 45 & 45 \\
\hline IO $(\%)$ & \multicolumn{3}{|}{} \\
\hline
\end{tabular}

Nilai IO dapat diketahui dari jumlah ovitrap positif per jumlah ovitrap yang diobservasi, dalam penelitian ini diperoleh hasil IO sebesar 36,66. Angka tersebut menurut Food and Environmental Hygiene Department (FEDH) Hongkong dalam Sze (2007) menunjukkan bahwa nilai Indeks Ovitrap yang dipasang di wilayah RT 04 RW 04 Mersi berada dalam Level 3 karena berada pada range $20 \% \leq$ OI $<40 \%$ dengan skor 3 yaitu masuk kriteria sedang, yang berarti memiliki potensi kerawanan DBD sedang dan perlu diadakan tindakan pemberantasan vektor.

Hasil uji Kruskal wallis menunjukkan nilai probabilitas korelasi yakni sig-2 tailed 0,00 lebih kecil dari taraf signifikan $(\alpha) \quad 0,05$ kriteria sedang pada level 3 dengan skor 3. Data penangkapan jumlah telur nyamuk biasanya disajikan dalam skala IO (Indeks Ovitrap) yang tersaji dalam Tabel 4.4 berikut : maka ada perbedaan jumlah telur nyamuk Aedes sp yang terperangkap pada ovitrap dalam masing-masing jenis atraktan yang digunakan, itu menunjukkan ada pengaruh antara variabel bebas terhadap variabel terikat. Air sumur lebih disukai oleh nyamuk karena lebih banyak menghasilkan telur yang terperangkap.Agustina mengemukakan karakteristik yang dimiliki air sumur menjadi daya tarik yang kuat bagi nyamuk betina untuk meletakkan telurnya.Hal ini sejalan dengan penelitian yang dilakukan oleh Fauziah (2012) air sumur berpotensi menjadi tempat perkembangbiakan nyamuk Aedes aegypti. Karakteristik yang dimiliki air sumur, seperti rendahnya salinitas dan kandungan bahan organik, $\mathrm{pH}$ 
pada kisaran netral, tingkat kekeruhan yang rendah (jernih), dan adanya kandungan bahan terlarut (total dissolved) sangat cocok untuk tempat hidup dan berkembangbiak Aedes aegypti pradewasa.

Penggunaan atraktan air rendaman cabai merah dalam penelitian ini memperoleh jumlah telur nyamuk yang terperangkap lebih banyak kedua setelah kontrol. Pada penelitian sebelumnya yang dilakukan di laboratorium oleh Rahayu dkk., (2015) menunjukkan bahwa pemakaian air rendaman cabai merah $15 \%$ sebagai bahan atraktan yang paling efektif jika dibandingkan dengan konsentrasi lainnya. Pada penelitian tersebut diketahui air rendaman cabai merah mengandung ammonia $0,86 \% \mathrm{mg} / \mathrm{l}, \mathrm{CO} 2$ total 12,4 $\mathrm{mg} / \mathrm{l}$, asam laktat 13,2 $\mathrm{mg} / \mathrm{l}$, octenol $0,7 \mathrm{mg} / \mathrm{l}$ dan asam lemak 22,8 mg/l lebih disukai nyamuk dibandingkan dengan kontrol (aquades). Penelitian tersebut menyebutkan atraktan cabai merah dengan konsentrasi 15\% dapat menangkap 24 nyamuk lebih tinggi dibandingkan dengan atraktan dengan konsentrasi lainnya.Namun fakta di lapangan menunjukkan jumlah telur yang dihasilkan oleh penggunaan atraktan cabai merah tidak dapat memerangkap telur nyamuk lebih banyak dari pada kontrol, sehingga membuktikan bahwa cabai merah tidak efektif digunakan sebagai bahan penarik (atraktan) nyamuk untuk bertelur. Penggunaan atraktan lain yaitu larutan gula-ragi dengan konsentrasi berat gula 50 gram dalam penelitian ini memperoleh jumlah telur nyamuk paling sedikit. Hasil penelitian ini menunjukkan bahwa atraktan gula-ragi tidak efektif sebagai bahan atraktan karena tidak dapat menghasilkan telur yang terperangkap lebih banyak daripada kontrol. Namun hasil ini berbeda dengan hasil penelitian yang dilakukan oleh Setiadi dan Slamet (2013) bahwa pada konsentrasi gula 50 gram menunjukkan konsentrasi $\mathrm{CO} 2$ yang optimal karena pada tahap ini merupakan fase statis dimana jumlah populasi sel tetap karena jumlah sel yang tumbuh sama dengan jumlah sel yang mati. Penelitian tersebut menyebutkan bahwa $\mathrm{CO} 2$ dapat menjadi daya tarik nyamuk. Pada penelitian ini fermentasi gula-ragi direndam secara anaerob selama 2 jam, berbeda 
dengan penelitian yang dilakukan oleh Kernelita dkk., (2014) yang melakukan fermentasi gula-ragi secara aerob selama satu minggu yang memungkinkan proses fermentasi akan lebih berjalan optimum apabila dilakukan lebih lama untuk menghasilkan gas $\mathrm{CO} 2$, asam laktat dan alkohol yang terbukti dapat dijadikan bahan atraktan yang disenangi nyamuk.

Perlakuan peletakan ovitrap di dalam dan di luar rumah sebesar 0,741 dengan $\alpha=0,05$ dan diperoleh pvalue sebesar $0,446>0,05$ sehingga tidak ada perbedaan jumlah telur nyamuk Aedes sp yang terperangkap berdasarkan peletakan ovitrap di dalam dan di luar rumah. Jumlah telur yang terperangkap di luar rumah lebih banyak dibandingkan dengan telur yang terperangkap di dalam rumah.Pada penelitian ini nyamuk Aedes sp lebih banyak meletakan telurnya di luar rumah. Dilihat dari perilaku kebiasaan hidup nyamuk Aedes aegypti lebih menyenangi hidup dan beristirahat di dalam rumah sedangkan Aedes albopictus sebaliknya lebih menyukai habitat di luar rumah, karena nyamuk ini adalah nyamuk spesies hutan yang beradaptasi dengan lingkungan manusia di pedesaan, semi perkotaan dan perkotaan (Rosa, 2007). Hasil ini didukung oleh penelitian Budiyanto (2012) yang menyatakan bahwa nyamuk Aedes aegyti lebih banyak ditemukan di dalam gedung, dan nyamuk Aedes albopictus lebih senang beristirahat di luar gedung. Perilaku hidup Aedes aegypti yang lebih suka beristirahat di tempat yang gelap, lembab dan tersembunyi di dalam rumah/bangunan, dan juga perilaku makan nyamuk Aedes aegypti sangat antropofilik.Perilaku Aedes albopictus sebaliknya, nyamuk ini lebih suka hidup di luar rumah karena pada dasarnya adalah spesies hutan yang beradaptasi dengan lingkungan manusia dan merupakan penghisap darah yang acak dan lebih zoofagik.

\section{SIMPULAN DAN SARAN}

Atraktan air rendaman cabai merah 15\% dan gula-ragi 50:1 tidak efektif menarik nyamuk Aedes $s p$ untuk bertelur, karena tidak dapat menghasilkan telur yang terperangkap lebih banyak dari kontrol (air sumur).Terdapat 
perbedaan jumlah telur nyamuk Aedes sp yang terperangkap pada ovitrap dalam masing masing atraktan. Terdapat lebih banyak telur nyamuk Aedes sp yang terperangkap di luar rumah dibandingkan di dalam rumah, namun perbedaan jumlah keduanya tidak signifikan. Perlu kajian lebih lanjut mengenai senyawa kimia yang terdapat pada air rendaman cabai merah $15 \%$ dan fermentasi gula-ragi sebagai bahan atraktan, serta perlu dikembangkan mengenai jenis atau formulasi bahan nabati lain yang berpotensi sebagai atraktan.

\section{DAFTAR PUSTAKA}

Achmadi, U., 2008, Penyakit Berbasis Wilayah, Universitas Indonesia (UI Press), Jakarta

Agustina, e., 2013, Pengaruh Media Air Terpolusi Tanah terhadap Perkembangbiakan Nyamuk Aedes aegypti, Jurnal Biotik, ISSN: 2337-9812, Vol. 1, No. 2, Ed. September 2013, Hal. 67-136, Banda Aceh

Astuti, E., dan Nusa, R., 2011, Efektifitas Alat Perangkap (Trapping) Nyamuk Vektor Demam Berdarah Dengue dengan Fermentasi Gula, Jurnal Aspirator Vol. 3 No. 1 Tahun 2011:41-48 Loka Litbang P2B2 Ciamis, Jawa Barat

Budiyanto, A., 2012, Perbedaan Warna Kontainer Berkaitan dengan Keberadaan Jentik Aedes aegypti di Sekolah Dasar, Loka Litbang P2B2 Baturaja, Ciamis

Fauziah, N.F., 2012, Karakteristik Sumur Gali dan Keberadaan Jentik Nyamuk Aedes aegypti, Jurnal Kesehatan Masyarakat ISSN
1858-1196 hlm $81 \quad-\quad 87$ http://journal.unnes.ac.id/nju/index.php/kem as, Semarang

Fauziah, N.F., 2012, Karakteristik Sumur Gali dan Keberadaan Jentik Nyamuk Aedes aegypti, Jurnal Kesehatan Masyarakat ISSN 1858-1196 hlm $81 \quad-\quad 87$ http://journal.unnes.ac.id/nju/index.php/kem as, Semarang

Kementerian Kesehatan Republik Indonesia, 2015, Profil Kesehatan Indonesia Tahun $2015 . \quad$ Jakarta: http://www.depkes.go.id/resources/downloa d/pusdatin/profil-kesehatan-indonesia/profilkesehatan-indonesia-2014.pdf. Diakses pada tanggal 29 Pebruari 2016

Kernelita, D., Mulyani, Sri., Widada, A., 2014, Pengendalian Nyamuk Aedes spp Menggunakan Perangkap Alamiah, Jurnal media Kesehatan Volume 7 Nomor 1 hlm 01 - 99 ISSN 1979 - 5750, Bengkulu

Pedrosa EA., 2010, Impact of small variations in temperature and humidity on the reproductive activity and survival of Aedes aegypti (Diptera, Culicidae), Jurnal Revista Brasileira de Entomologia vol 54 no 3

Rahayu, S., Bayu, W., Lailly N., Mobarak, A., 2015, Uji Kefektifan Atraktan oryza sativa, capsicum annum, trachisperum roxburgianum pada Trapping nyamuk Aedes Aegypti. Semarang: Fakultas Kesehatan Masyarakat Universitas Diponegoro.

Rosa, E., 2007, Studi Tempat Perindukan Nyamuk Vektor Demam Berdarah Dengue Di Dalam Dan Di Luar Rumah Di Rajabasa Bandar Lampung, FMIPA Universitas Lampung J. Sains MIPA, April 2007, Vol. 13, No. 1, Hal.: 57 - 60 ISSN 1978-1873, Lampung

Setiadi, F., Slamet, 2013, Pengujian Alat Perangkap Nyamuk Berbasis Fotokatalisis dengan Tambahan Sumber Penghasil CO2, Departemen Teknik Kimia, Fakultas Teknik, Universitas Indonesia, Jakarta

Sze, WN., Yan, LC., Kwan, LM., Shan, LS \& Hui L., 2007, An Alert System For Informing Environmental Risk Of Dengue Infections, GIS For Health And The Environment Springer-Verlag, Berlin Heidelberg 